\title{
Shear Strength of Unsaturated Soils with Different Plasticity
}

\author{
Alaa El-Hosani Refai Kassab ${ }^{1, *}$, Azza Hassan Moubark ${ }^{2}$, Waleed Hamdy \\ Elkamash $^{3}$ and Kamal Mohamed Hafez Ismail ${ }^{4}$. \\ ${ }^{1}$ Ph.D. student, Department of Civil Engineering- Faculty of Engineering- Suez Canal \\ University - Ismailia - Egypt. \\ ${ }^{2}$ Associate Prof, Department of Civil Engineering- Faculty of Engineering- Suez Canal \\ University - Ismailia - Egypt. \\ ${ }^{3}$ Associate Prof, Department of Civil Engineering- Faculty of Engineering-Suez Canal \\ University - Ismailia - Egypt. \\ ${ }^{4}$ Professor, Department of Civil Engineering- Faculty of Engineering-Suez Canal University \\ - Ismailia - Egypt. \\ 1,* ${ }^{*}$ alaa.kassab@eng.suez.edu.eg, ${ }^{2}$ Azza_moubarakl.@eng.suez.edu.eg \\ ,${ }^{3}$ Waleedelkamash@eng.suez.edu.eg, ${ }^{4}$ Kamal.hafez@eng.suez.edu.eg
}

\begin{abstract}
A series of shear box tests were conducted on four different types of soils in this study. The first set , (clay 1$)$ is the host clay, Middle Delta Nile clay "MDNC" which was obtained from Mid Delta Nile zone, Qalyubiyya Governorate, Egypt. The second set, $\left(\right.$ clay $\left._{2}\right)$ consists of the host clay MDNC but mixed with $40 \%$ sand. The third set of tests (clay $)_{3}$ was carried out on natural low plastic clay samples brought from El-Tal El-Kbeer area in Ismailia Governorate. The fourth set (clayey sand-SC) consists of $25 \%$ of the host clay MDNC mixed with 75\% sand. The purpose is to predict the unsaturated shear strength for various soil types. The results illustrate that for clay ${ }_{1}$, clay $_{2}$, and clay $y_{3}$, the relationships between the unsaturated shear strength and matric suction are approximated to two linear failure envelopes intersected at matric suction equals to plastic limit. Each segment has an angle of internal friction due to matric suction $\phi_{1}{ }^{b}$ ranging from $1.80^{\circ}$ to $2.90^{\circ}$ for the first zone and $\phi_{2}{ }^{b}$ ranging from $0.28^{\circ}$ to $0.20^{\circ}$ for the second zone. Meanwhile, for SC soil it appears to have one linear failure envelope for all saturation levels with angle of internal friction due to matric suction; $\phi^{b}=1.19^{\circ}$. DesignExpert ${ }^{\circledR}$ software applied the least square method (LSM) to fit a mathematical model for the experimental data. The Response Surface Methodology (RSM) of the program is used to predict the required model. The paper proposed two general equations to calculate the shear strength of unsaturated clays and one equation for granular soils, which are presented at the end of the paper with their coefficients.
\end{abstract}

Keyword: Response Surface Methodology, Middle Delta Nile clay, shear strength of unsaturated clay, clayey sand soil and, matric suction 


\section{1- Introduction}

Several models have been proposed to predict the shear strength of unsaturated soils at different values of matric suction [1]. During the last 50 years, several methods are investigated to predict the shear strength of unsaturated soils. [2] modified the conventional direct shear testing apparatus to determine the soil water characteristic curve (SWCC) and the shear strength behavior of four types of sand. More recently, [3] investigated the relation between unsaturated shear strength parameters and soil properties to predict the unsaturated shear strength parameters $\left(c^{\prime}, \phi^{\prime}\right.$ and $\left.\phi^{b}\right)$. [4] presented a summarized approaches for predicting or estimation the shear strength of unsaturated soils by several investigators. [5] summarized and presents 46 approaches proposed equations for predicting or estimating the shear strength of unsaturated soils. [6] used the results of direct shear box tested on high plastic unsaturated clay to investigate the behavior of unsaturated clay due to the variation of matric suction. The study appears a nonlinear relation between matric suction and unsaturated shear strength. That non-linear failure envelope for unsaturated shear strength and matric suction is approximated to two linear zones. the deviation at intersection point was estimated at matric suction at water content equals to the plastic limit .

Soil suction is one of the most important parameters describing the moisture condition of unsaturated soils. [7 ] explains the methods to define the soil water characteristic curve $(S W C C)$ for a soil. Those methods can classified as either direct or indirect. Direct methods include pressure plate, pressure membranes and tensiometers, where. Indirect methods include filter paper, pours blocks and heat dissipation sensors. [8] states that most of instruments used for measuring matric suction have limitations with regard to range of measurement, equilibration times, and cost. [9] explained that the filter paper method is a soil suction measurement technique is an inexpensive method and relatively simple laboratory test method. [10] explain that using the gravimetric water content " $W$ ", which is the ratio of mass of water to the mass of solids is mostly used in geotechnical engineering practice. The degree of saturation $S$ is another method to be used in defining the soil-water characteristic curve $S W C C$. [11] studied the effect of matric suction on the shear strength of highly plastic compacted clay, they concluded that the shear strength of the tested clay increase with the increase of matric suction in nonlinear form. [12] used the Design-Expert program to calculate the ultimate lateral capacity of large diameter monopiles embedded in sand. Design-Expert program is a statistical software package from Stat-Ease Inc. That program is specifically dedicated to perform design of experiments and offers comparative tests, screening, characterization, optimization, robust parameter design, mixture designs and combined designs. It provides test matrices for screening up to 50 factors. Statistical significance of these factors are established with analysis of variance (ANOVA). In this paper the program used to predict a unique equation to calculate the shear strength of unsaturated soils SSUS using results of series of tests of direct shear box on three types of cohesive soils and one granular soil under controlled suction. 


\section{2-Experimental Preparation and Test Procedure}

\subsection{Test materials and Sample Preparation}

Three sets of remolded clay and one set of clayey sand soil were tested using a series of shear box tests on four different soil samples. Table -1 lists the characteristics of the four sets. Figure-1a depicts the grain size distribution of sand, while Figure-1b depicts the grain size distribution of host clay MDNC, clay $_{3}$ and El-Golf clay as determined by hydrometer testing. El-Golf clay is used to verification the equation of determinate the unsaturated shear strength of unsaturated soils. To obtain $\phi_{1}^{b}$ and $\phi_{2}^{b}$, four groups of tests were performed at net vertical stress $\sigma_{\mathrm{v}}=65 \mathrm{kpa}$ for each group and with different values of matric suction. Then there were four more groups of tests, each with a different vertical stress value and the same matric suctions. For each soil group of tested soil, the matric suction values are as follows: $\psi_{1}=6000 \mathrm{kpa}$ for clay ${ }_{1}, \psi_{2}=4000 \mathrm{kpa}$ for clay ${ }_{2}, \psi_{3}=3000$ $\mathrm{kpa}$ for $\mathrm{clay}_{3}$, and $\psi_{4}=400 \mathrm{kPa}$ for SC soil. As a result, the values of $\phi$, c can be deduced from test results.

Table 1. Properties of Tested Soils

\begin{tabular}{|c|c|c|c|c|}
\hline Property & Clay $_{1}$ & Clay $_{2}$ & Clay $_{3}$ & SC soil \\
\hline Liquid limit & $63 \%$ & $41 \%$ & $38 \%$ & $=======$ \\
\hline Plastic limit & $25 \%$ & $20 \%$ & $19 \%$ & ======= \\
\hline Plasticity index & $38 \%$ & $21 \%$ & $19 \%$ & $======$ \\
\hline Shrinkage limit & $14 \%$ & $15 \%$ & $16 \%$ & $=======$ \\
\hline Classification & $\mathrm{CH}$ & $\mathrm{CL}$ & $\mathrm{CL}$ & $\mathrm{SC}$ \\
\hline Clay fraction & $10 \%$ & $6 \%$ & $5 \%$ & $3 \%$ \\
\hline Silt fraction & $77 \%$ & $46 \%$ & $46 \%$ & $23 \%$ \\
\hline Sand fraction & $13 \%$ & $48 \%$ & $49 \%$ & $74 \%$ \\
\hline
\end{tabular}



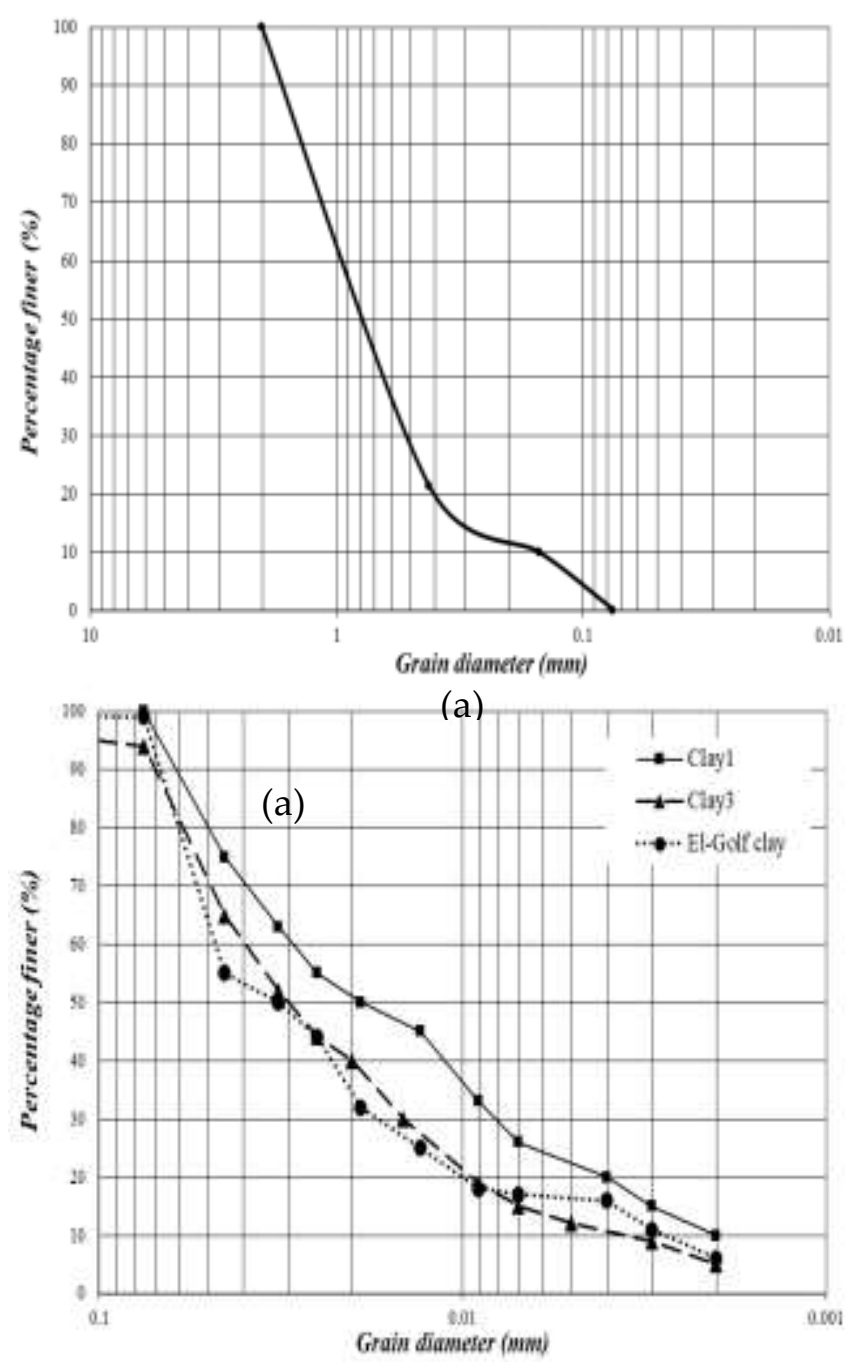

(b)

Figure -1. Grain size distribution: (a) sieve analysis for sand; (b) hydrometer test for clay, clay $_{3}$ and El-Golf clay

\subsection{Measurement of Matric Suction}

Most of matric suction technique instruments have limitations with respect to range of measurement, reaching time of equilibration and cost. One of the soil suction measurement techniques is the filter paper method, which was evolved in Europe in the 1920s and the United States of America in 1937 by [13] .So, this technique was used in this research. Twenty samples from each clay type were prepared in cylinder moulds. The samples slowly dried by exposing to air in partially covered plastic container Samples were kept in a labeled jars and taped from top to prevent any moisture exchange between the air inside and the air outside of the jar. Then measuring the water content of filter paper using sensitive balance with accuracy of $0.001 \mathrm{gm}$ and using the calibration curves 
suggested by[14] to calculate the corresponding matric suction . [15] used the contact filter paper technique. Figure-2 illustrates set up for samples and filter paper.
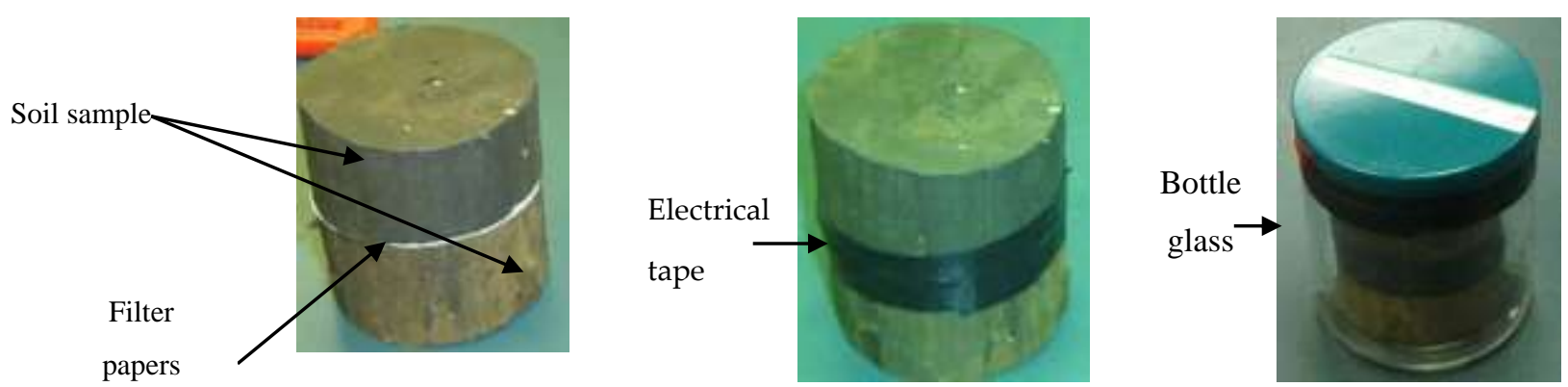

Figure-2 Set up for contact filter paper technique (Uchaipichat and Mankoksung, 2011).

\section{Results and Discussions}

\subsection{Soil Water Characteristic Curve}

From results of matric suction predicted by filter paper technique and by using the calibration chart of filter paper Whatman 42. Figure-3 illustrates the Soil-Water Characteristic Curves (SWCC) for the four types of soil. From Figure-3 the values of matric suction at plastic and shrinkage limit for each soil is presented in Table-2. 

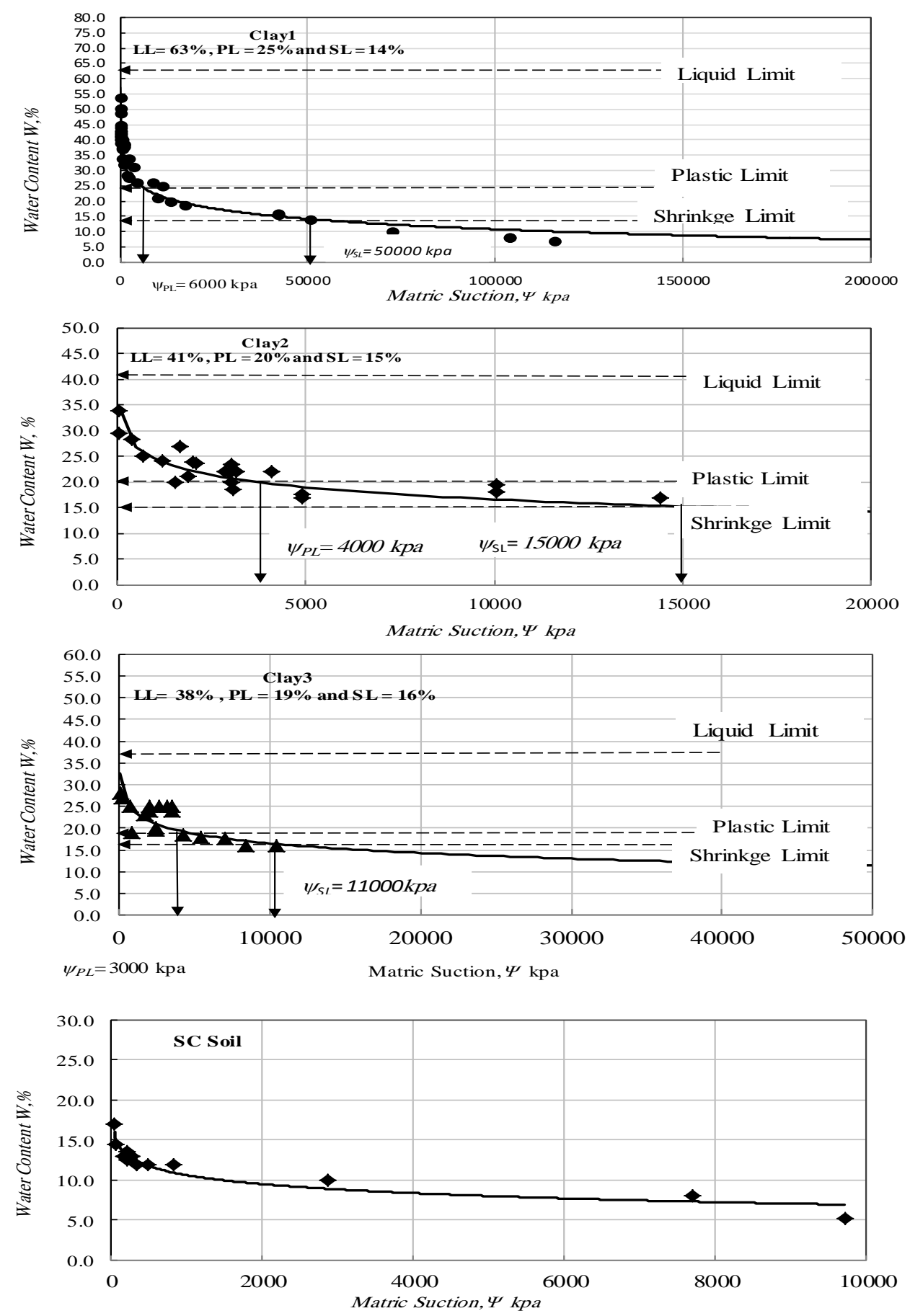

Figure -3 Soil -Water Characteristic Curve (SWCC) for Clay1, Clay2, Clay3 and SC Soil. 
Table-2 Matric suction at shrinkage and plastic limits for soils

\begin{tabular}{|l|c|c|}
\hline \multicolumn{1}{|c|}{ Soil Type } & Suction at plastic limit (kpa) & Suction at shrinkage limit $(\mathrm{kpa})$ \\
\hline Clay $_{1}$ & $\psi_{P L}=6000$ & $\psi_{S L}=50000$ \\
\hline Clay $_{2}$ & $\psi_{P L}=4000$ & $\psi_{S L}=15000$ \\
\hline Clay $_{3}$ & $\psi_{P L}=3000$ & $\psi_{S L}=11000$ \\
\hline SC Soil & $========$ & $=======$ \\
\hline
\end{tabular}

\subsection{Direct Shear Box Results}

All direct shear box samples were tested in steel mold of $60 \mathrm{~mm} \times 60 \mathrm{~mm}$ and $20 \mathrm{~mm}$ (height). Four sets of tests contain sixty remolded samples for the four sets of Clayl, Clay2, Clay3 and SC soil. The samples were tested in direct shear box apparatus at different values of matric suction and net vertical stress $65 \mathrm{kpa}$. Figure-4 shows the constant humidity plastic box and the stages for preparing samples for testing. The main parts of direct shear box assembly are shown in Figure-5. Figure -6 shows sample inside shear box and the sample after shearing. Another four groups of samples contain six samples for each group were tested at values of suction as follow: $\psi=1600 \mathrm{kpa}$ for clay and $\psi=4000 \mathrm{kpa}$ for $\mathrm{clay}_{2}, \psi=3000 \mathrm{kpa} \mathrm{clay}_{3}$ and $\psi=400 \mathrm{kpa}$ for SC soil. Each group was tested at different six net vertical stress $\sigma_{\mathrm{v}}$, in the range of (zero to $200 \mathrm{kpa}$ ) to determinate the value of angle of internal friction, $\phi$ for the four soils.

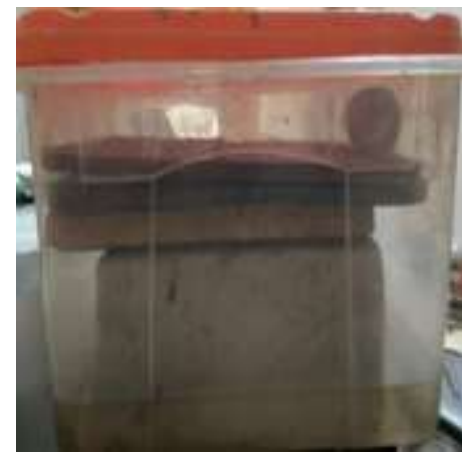

1-Partially open cover box for slow drying and keeping samples without cracks

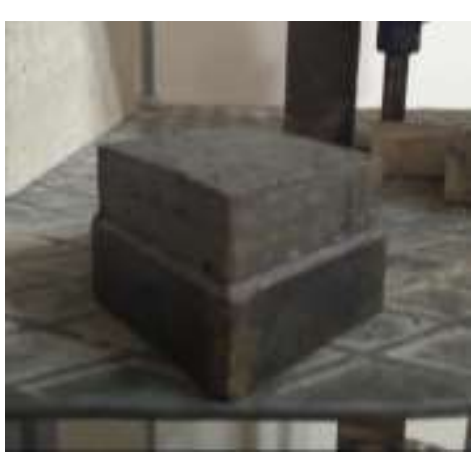

2-Sample inside mould and before shearing

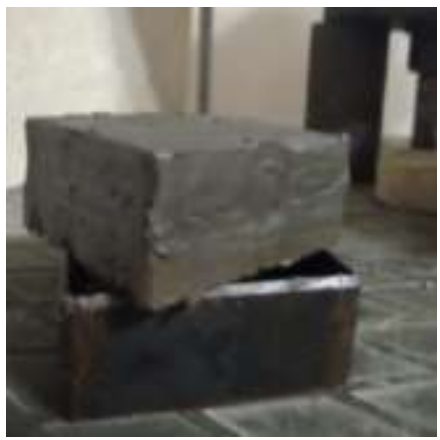

3-Sample after extracted from mould

Figure -4 Stages of preparation of shear box samples 


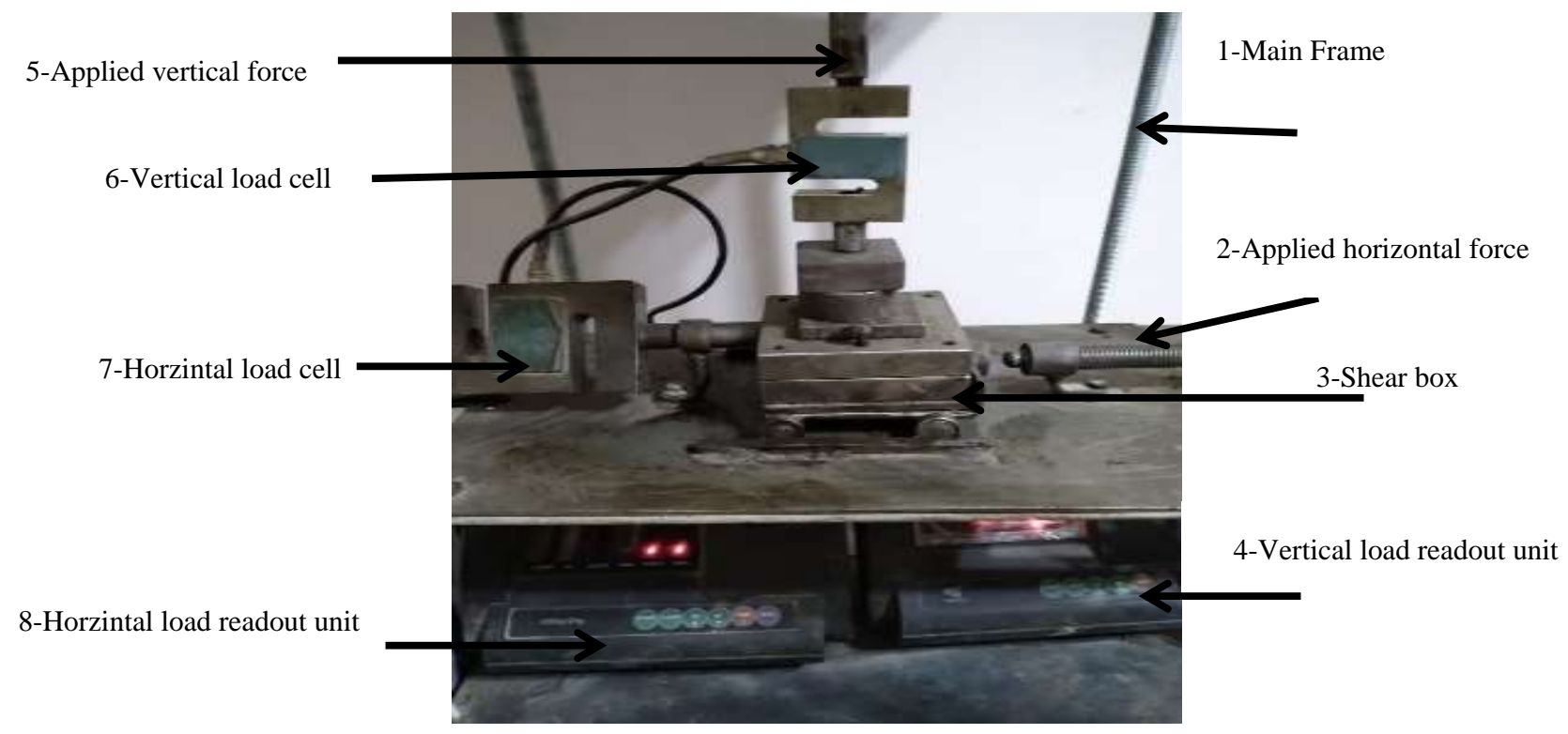

Figure -5 Shear box assembly

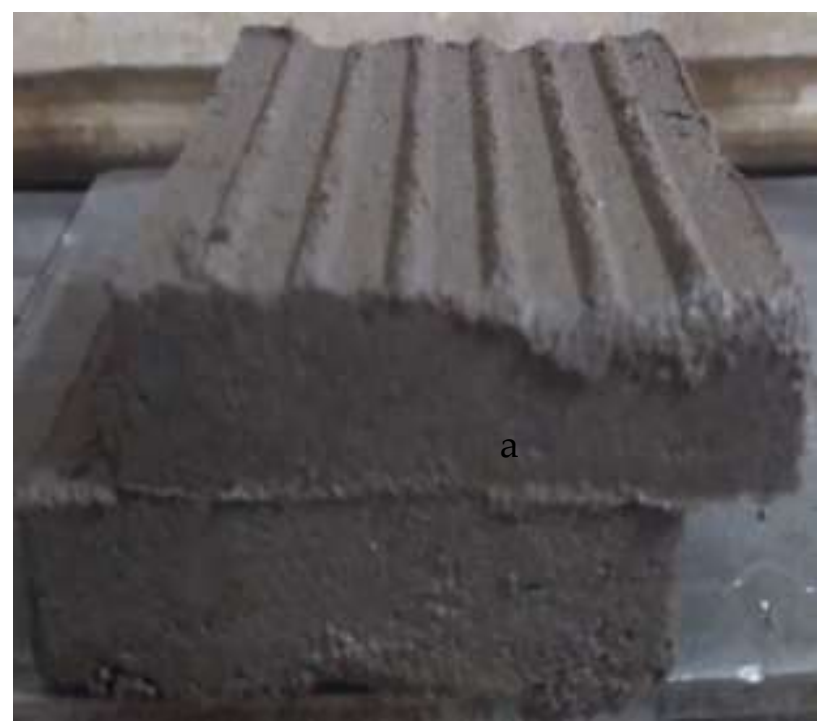

Figure -6 Sample after shearing and extracting from shear box

Figure -7 shows the relation between the shear strength of unsaturated soils and the corresponding matric suction for the four types of soil. The first three curves of clays are approximated to two straight lines. Only SC soil behaves as granular material and the shear envelope is represented by one equation and one zone. The tests of direct shear box were performed at vertical stress $\sigma_{v}=65 \mathrm{kpa}$. 

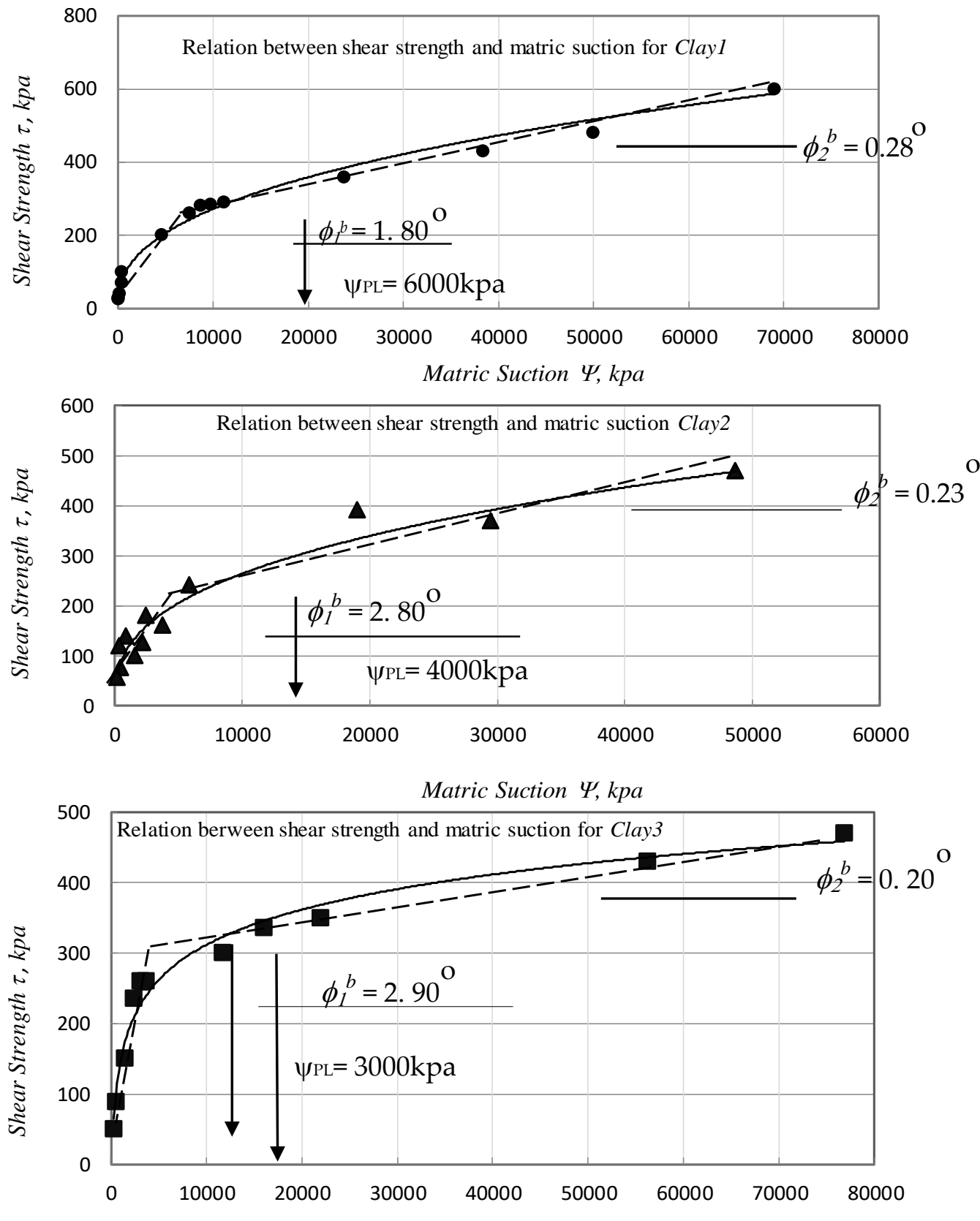

Matric Suction $\Psi, k p a$

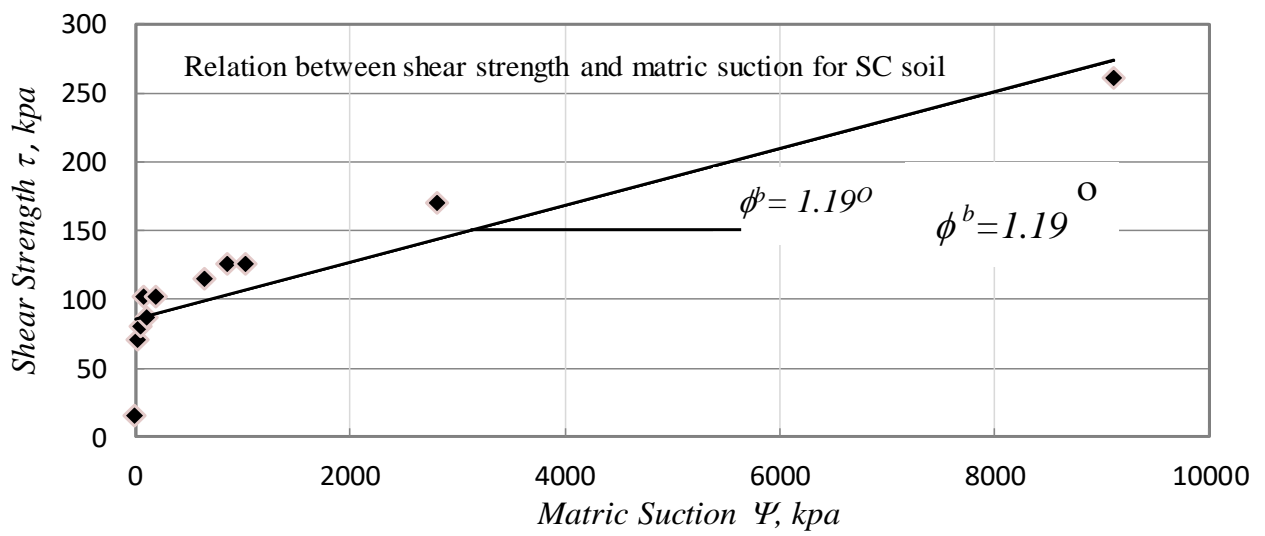


Figure -7 Shear Strength Variation with Matric Suction for the four types of soil at vertical stress $=65 \mathrm{kpa}$

Table-3 Values of Angle of Internal Friction with respect to Matric Suction at

$$
\sigma_{\mathrm{v}}=\boldsymbol{k p a}
$$

\begin{tabular}{|l|c|c|}
\hline Soil Type & $\phi_{1}{ }^{\text {}}$ (deg.) & $\phi_{2}^{\text {b }}$ (deg.) \\
\hline Clay1 & 1.80 & 0.28 \\
\hline Clay2 & 2.80 & 0.23 \\
\hline Clay3 & 2.90 & 0.20 \\
\hline SC soil & \multicolumn{2}{|c|}{1.19} \\
\hline
\end{tabular}

The second group of tests were performed at different vertical stresses and one controlled value of plastic limit matric suction for each group. The purpose of these tests is determinate the cohesion and the internal angle of friction for each soil. Results of tests are shown in Figure- 8 and the measured internal angle of friction and cohesion are presented in Table- 4 . The values of effective cohesion for each soil are presented in table 4 

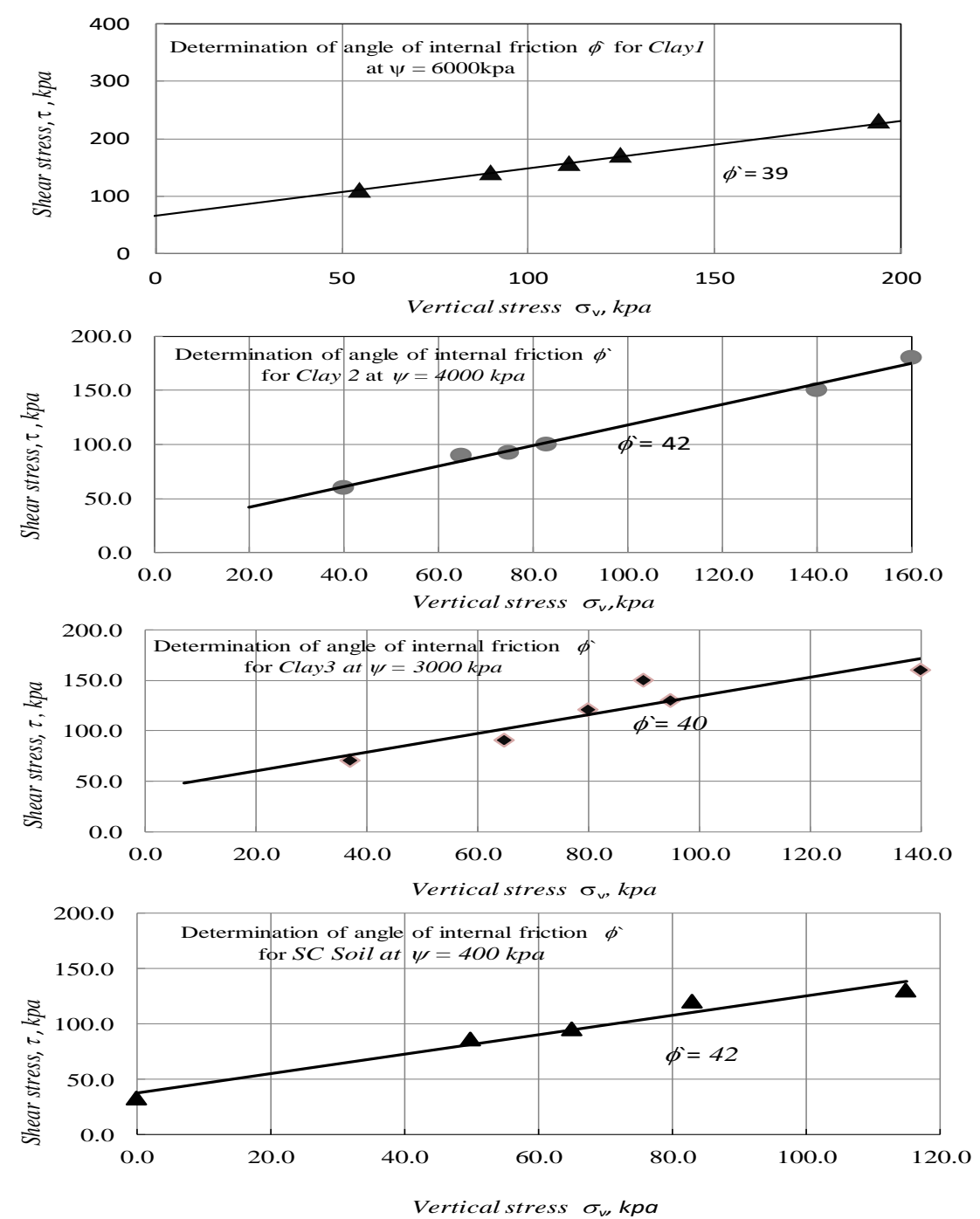

Figure-8 Variation of angle of internal friction, $\phi$ and cohesion, $c$ at matric suction at plastic limit 
Table- 4 Cohesion and internal angle of friction for at plastic limit of soils

\begin{tabular}{|c|c|c|c|c|c|}
\hline $\begin{array}{c}\text { Type of } \\
\text { Soil }\end{array}$ & $\begin{array}{c}c(\mathrm{kpa}) \\
\text { at } \Psi=\Psi_{p l}\end{array}$ & $\begin{array}{c}\phi^{\prime}(\mathrm{deg} .) \\
\text { at } \Psi=\Psi_{p l}\end{array}$ & $\begin{array}{c}c^{\prime}(\mathrm{kpa}) \\
\text { at } \Psi=0\end{array}$ & $\Psi_{p l}(\mathrm{kpa})$ & $\Psi_{s l}(\mathrm{kpa})$ \\
\hline Clay $_{1}$ & 70 & 39 & 8.5 & 6000 & 50000 \\
\hline Clay $_{2}$ & 30 & 42 & 7 & 4000 & 15000 \\
\hline Clay $_{3}$ & 42 & 40 & 5.5 & 3000 & 11000 \\
\hline SC Soil & 38 & 42 & 3 & $===============$ \\
\hline
\end{tabular}

\subsection{Mathematical Model}

Design-Expert ${ }^{\circledR}$ software employs least square method (LSM) which is a multiple regression technique used to fit a mathematical model to a set of experimental data and generating the lowest residual using the Response Surface Methodology (RSM). The program used to get an equation for zone I and zone II to evaluate the shear strength of unsaturated soils. The equations contain three variable parameters (c', $\sigma_{v}$ and $\psi$ ) which mainly have the main impact on shear strength of unsaturated soils. The program used the actual results from direct shear box to fix two equations for calculate the unsaturated shear strength for the four types of soils as the following:

The two equations produced from Response Surface Methodology for Clay ${ }_{1}$ are as follows:

$$
\begin{array}{ll}
\tau_{\text {Iun }}=8.0 c^{`}+0.40\left(\sigma_{v}\right) \tan \phi+(\psi) \tan \phi^{b_{1}} & \text { Zone I, for } P L<W c<L L \ldots \text { (1) } \\
\tau_{2 \text { un }}=22.0 c^{`}+\left(\sigma_{v}\right) \tan \phi+(\psi) \tan \phi^{b_{2}} & \text { Zone II, for } W c<P L \ldots \ldots \ldots \text { (2) }
\end{array}
$$

Equations (1) and (2) are represented in three models and illustrates in Figure 9a and b 


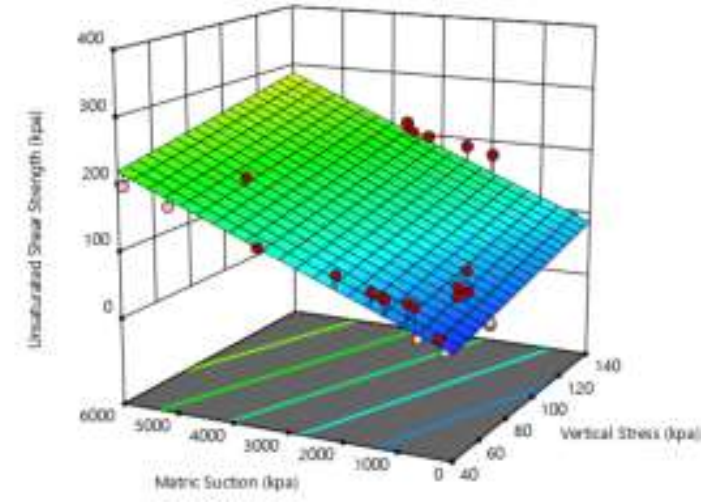

(a) Equation (1)for first zone I ( $\left.\mathrm{R}^{2}=0.86\right)$

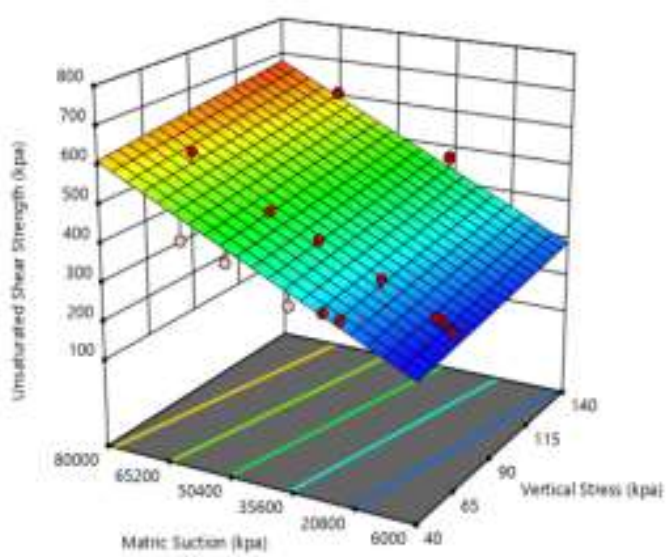

(b) Equation (2) for second zone I $\left(\mathrm{R}^{2}=0.99\right)$

Figure- 9 Shear strength of unsaturated Clay1:(a) Zone(I);(b) Zone(II)

The results obtained from shear box tests for $\mathrm{Clay}_{2}$ produces equations (3) and (4) for zone I and zone II. Three dimension figures for equations (3) and (4) are shown in Figure-10 a and b

$$
\begin{aligned}
& \tau_{\text {1un }}=10.0 c^{`}+0.20\left(\sigma_{v}\right) \tan \phi \phi^{`}+(\psi) \tan \phi^{b_{1}} \text { Zone I, for } P L<W c<L L \ldots(3) \\
& \tau_{2 \text { un. }}=40.0 c^{`}+\left(\sigma_{v}\right) \tan \phi+(\psi) \tan \phi^{b_{2}} \quad \text { Zone II, for } W c<P L \ldots \ldots \ldots \text { (4) }
\end{aligned}
$$

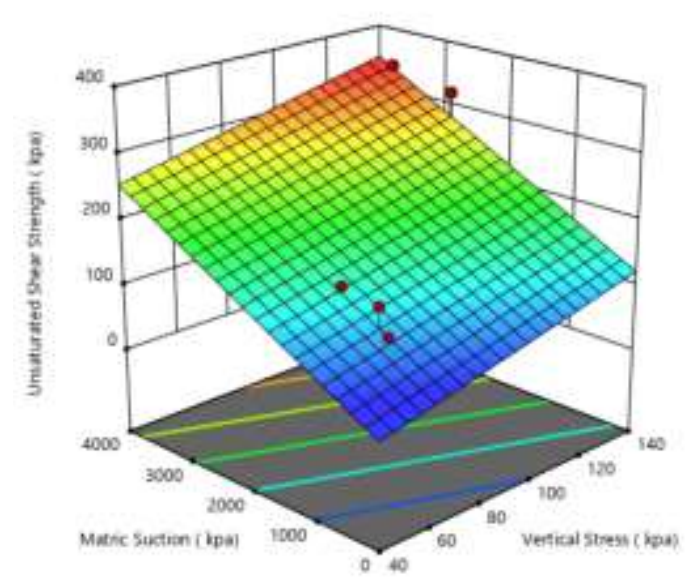

(a) Equation 3 first zone I for $\operatorname{clay}_{2}\left(R^{2}=0.960\right)$

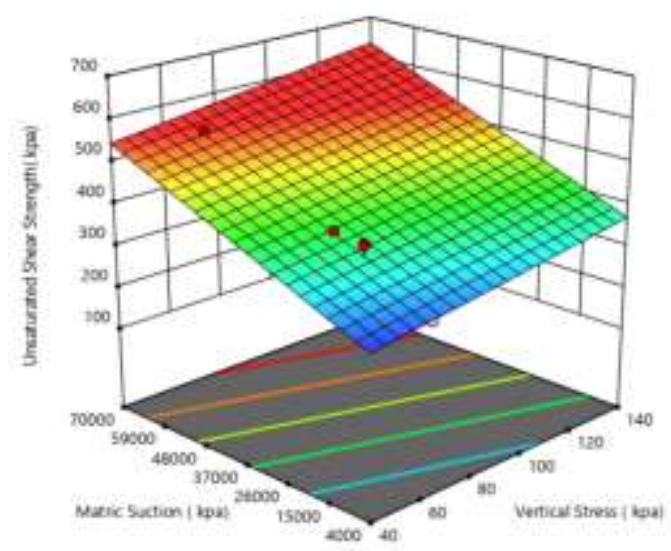

(b) Equation 4 zone II for $\operatorname{clay}_{2}\left(\mathrm{R}^{2}=0.94\right)$

Figure- 10 Shear strength of unsaturated Clay2: (a) Zone (I);(b) Zone(II)

Data results of shear box tests on $\mathrm{Clay}_{3}$ were analyzed by Response Surface Method from Design Expert Program producing equations 5 \& 6 which represented in in Figure 11a and b

$$
\begin{aligned}
& \tau_{\text {lun }}=10.0 c^{2}+0.20\left(\sigma_{v}\right) \tan \phi \dot{\phi}+(\psi) \tan \phi_{I}{ }^{b} \quad \text { Zone I from } P L<W c<L L \ldots \text {.. (5) } \\
& \tau_{2 u n .}=30.0 c^{`}+0.5\left(\sigma_{v}\right) \tan \phi+(\psi) \tan \phi_{2}^{b} \quad \text { Zone II, from } W c<P L \ldots \ldots \text { (6) }
\end{aligned}
$$




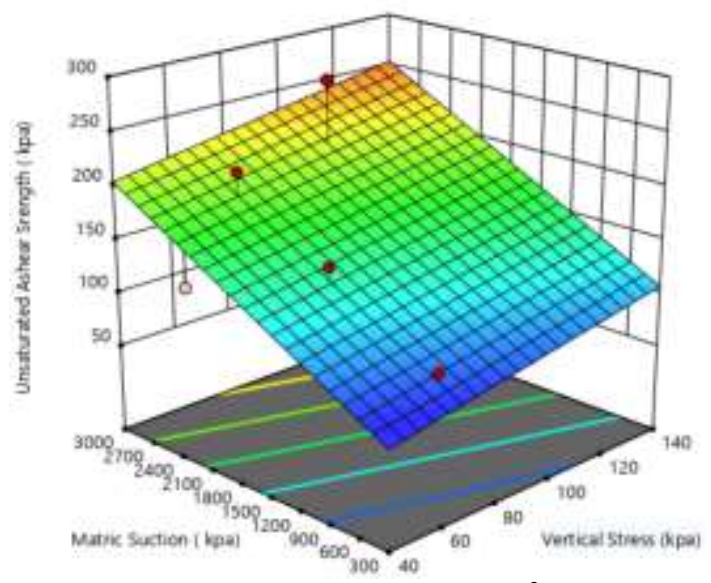

(a) Equation 5 first zone I for $\operatorname{clay}_{3}\left(R^{2}=0.70\right)$

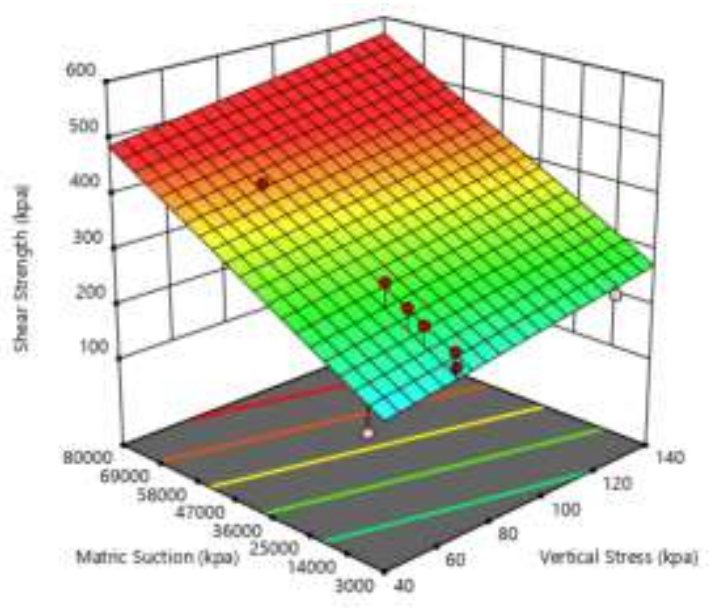

(b) Equation 6 second zone II for $\operatorname{clay}_{3}\left(\mathrm{R}^{2}=0.75\right)$

Figure- 11 Shear strength of unsaturated Clay3 :(a) Zone(I);(b) Zone(II)

For SC soil the results appears one zone as shown Figure -12 and presented by Equation (7) in Figure-12

$$
\tau_{u n}=10.0 c^{`}+0.90\left(\sigma_{v}\right) \tan \phi \phi^{`}(\psi) \tan \phi^{b} \text { for all values of water content ... (7) }
$$

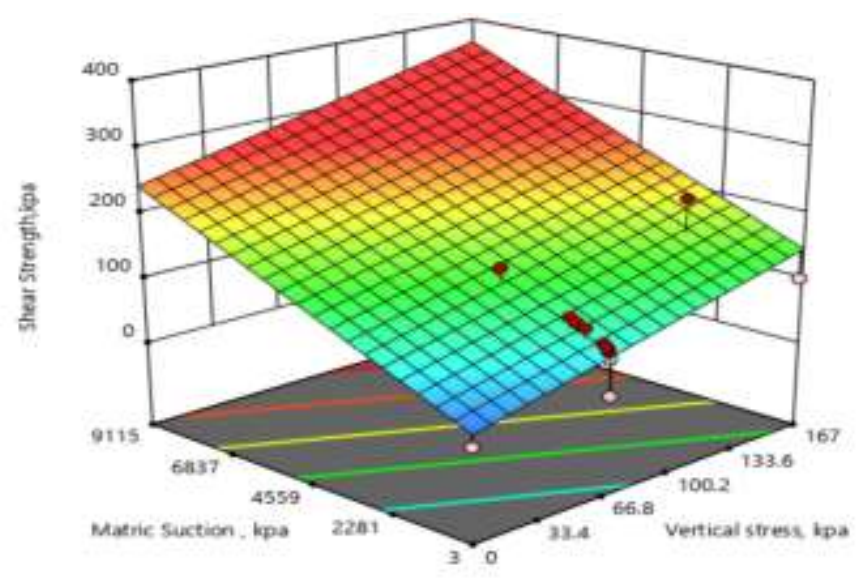

Linear Equation for $\mathrm{SC}$ soil $\left(\mathrm{R}^{2}=0.83\right)$

Figure- 12 Shear Strength of Unsaturated of SC soil

The previous seven equations predict the unsaturated shear strength of the four types of soil and are shown in Table 5 . 
Table- 5 Equations that predict the unsaturated shear strength for the four types of soil.

\begin{tabular}{|c|c|c|c|}
\hline $\begin{array}{l}\text { Soil } \\
\text { No. }\end{array}$ & $\begin{array}{l}\text { Soil } \\
\text { Description }\end{array}$ & $\begin{array}{l}\text { First zone }\left(\psi<\psi_{P L}\right) \text { equation for } \\
\text { determination shear strength } \tau_{\text {lun }}= \\
A_{l} c^{2}+B_{l}\left(\sigma_{v}\right) \tan \phi+(\psi) \tan \phi^{b}{ }_{I}\end{array}$ & $\begin{array}{l}\text { Second zone }\left(\psi>\psi_{P L}\right) \text { equation for } \\
\text { determination shear strength } \tau_{2 u n}= \\
A_{l} c^{-}+B_{I}\left(\sigma_{v}\right) \tan \phi+(\psi) \tan \phi^{b}\end{array}$ \\
\hline 1 & Clay $_{1}$ & $\begin{array}{l}8.0 c^{`}+0.40\left(\sigma_{v}\right) \tan \phi+(\psi) \\
\tan \phi^{b}{ }_{1}\end{array}$ & $22 c^{`}+\left(\sigma_{v}\right) \tan \phi+(\psi) \tan \phi_{2}^{b}$ \\
\hline 2 & $\mathrm{Clay}_{2}$ & $\begin{array}{l}10.0 c^{\prime}+0.20\left(\sigma_{v}\right) \tan \phi+(\psi) \\
\tan \phi_{1}^{b}\end{array}$ & $35 c^{`}+0.60\left(\sigma_{v}\right) \tan \phi+(\psi) \tan \phi_{2}^{b}$ \\
\hline 3 & $\mathrm{Clay}_{3}$ & $\begin{array}{l}10.0 c^{\prime}+0.20\left(\sigma_{v}\right) \tan \phi^{\prime}+\quad(\psi) \\
\tan _{1}^{b}{ }_{1}\end{array}$ & $30 c^{`}+0.50\left(\sigma_{v}\right) \tan \phi+(\psi) \tan \phi_{2}^{b}$ \\
\hline 4 & SC Soil & $10.0 c^{`}+0.90\left(\sigma_{v}\right) \tan \phi \phi^{`}+(\psi) \tan \phi^{b}$ & One zone only \\
\hline
\end{tabular}

In general, from the previous equations for cohesive soils the unsaturated shear strength will be in two divisions and will take the following forms:

$$
\begin{gathered}
\tau_{\text {lun. }}=A_{1} c^{`}+B_{1}\left(\sigma_{v}\right) \tan \phi \phi^{`}+(\psi) \tan \phi_{1}^{b} \text { Zone I from } P L<W c<L L \ldots \\
\tau_{2 \text { un. }}=A_{2} c^{`}+B_{2}\left(\sigma_{v}\right) \tan \phi+(\psi) \tan \phi_{2}^{b} \quad \text { Zone II, from } W c<P L \ldots .
\end{gathered}
$$

Where $A$ and $B$ and are coefficients related to (clay fraction, angle of internal friction and values of matric suction at plastic and shrinkage limit). Granular soils which contain fines (silt or clay) less than 35 percentage, one equation only will be used to determinate the unsaturated shear strength at any level of matric suction or at any degree of saturation. The equation for granular material can take the following form:

$$
\tau_{u n .}=A_{3} c^{2}+B_{3}\left(\sigma_{v}\right) \tan \phi \phi^{`}+(\psi) \tan \phi^{b}
$$

The values of factors $A_{1}, A_{2}, A_{3}, B_{1}, B_{2}$ and $B_{3}$ are summarized in Table 6

Table- 6 Values of factors A1, A2, A3, B1, B2 and B3

\begin{tabular}{|c|c|c|c|c|}
\hline Factor & \multicolumn{1}{|c|}{ Zone I } & Factor & \multicolumn{1}{|c|}{ Zone II } & Soil type \\
\hline$A_{1}$ & $\begin{array}{l}=1 \times \text { (The percentage of clay } \\
\text { fraction) }\end{array}$ & $A_{2}$ & $\begin{array}{l}=3 \times \text { (the percentage of clay } \\
\text { fraction) }\end{array}$ & CH soils \\
\hline$A_{1}$ & $\begin{array}{l}=2 \times \text { (the percentage of clay } \\
\text { fraction) }\end{array}$ & $A_{2}$ & $\begin{array}{l}=5 \times(\text { the percentage of clay } \\
\text { fraction) }\end{array}$ & CL soils \\
\hline$A_{3}$ & \multicolumn{2}{|c|}{$=5 \times$ xthe percentage of clay fraction } & $\begin{array}{l}\text { Granular } \\
\text { soils }\end{array}$ \\
\hline$B_{1}$ & $=0.5 \times\{1$ - (percentage of sand in soils) $/ 100\}$ for Zone I and Zone II & CH soils \\
\hline$B_{2}$ & $=\{1$ - (percentage of sand in soils)/100\} for Zone I and Zone II & CL soils \\
\hline$B_{3}$ & $=\{$ percentage of sand in soils $\} / 100$ & $\begin{array}{c}\text { Granular } \\
\text { soils }\end{array}$ \\
\hline
\end{tabular}




\subsection{Checking the Unsaturated Shear Strength Equation on Random Natural Trial} Soil

The soil water characteristic curve for El-Golf clay is presented in Figure-14, the matric suction presents in the following form $\psi=\mathrm{e}^{\{(70-\mathrm{W}) / 5.10\}}$. Results of direct shear box for arbitrary natural soil brought from Ismailia Governorate, Golf zone. The shear box test results for that clay are presented in Figure-15 and produce a value of $\phi_{1}^{b}$ and $\phi_{2}^{b}=2.8^{\circ}$ and $0.29^{\circ}$ respectively. Shear box tests were performed at vertical stress $=65 \mathrm{kpa}$. Due to the previous discussions, the equations for determinate the unsaturated shear strength of El-Golf clay can be given by:

$$
\begin{array}{ll}
\tau_{\text {lun. }}=A_{1} c^{`}+B_{1}\left(\sigma_{v}\right) \tan \phi+(\psi) \tan \phi_{I}{ }^{b} & \text { Zone I from } P L<W c<L L \ldots \\
\tau_{2 \text { un. }}=A_{2} c^{`}+B_{2}\left(\sigma_{v}\right) \tan \phi+(\psi) \tan \phi_{2}^{b} & \text { Zone II, from } W c<P L \quad \ldots . .
\end{array}
$$

The properties of El-Golf clay are presented in Table-7 and Figure1-b

Table-7 Properties of El-Golf Clay

\begin{tabular}{|c|c|c|c|c|c|c|c|c|c|c|c|c|}
\hline LL & PL & SL & $\begin{array}{c}\text { Clay } \\
\text { fractio } \\
\mathrm{n}\end{array}$ & $\begin{array}{c}\text { Silt } \\
\text { fractio } \\
\mathrm{n}\end{array}$ & $\begin{array}{c}\text { Sand } \\
\text { fractio } \\
\mathrm{n}\end{array}$ & $\begin{array}{c}\Psi_{p l} \\
(k p a \\
(\end{array}$ & $\begin{array}{c}\Psi_{S l} \\
(k p a)\end{array}$ & $\begin{array}{c}\text { Classificatio } \\
\mathrm{n}\end{array}$ & $\phi_{1}^{b_{1}}$ & $\phi_{2}^{b}$ & $\phi^{\prime}$ & $\begin{array}{c}c^{\prime} \\
(k p a \\
\end{array}$ \\
\hline $\begin{array}{c}58 \\
\%\end{array}$ & $\begin{array}{c}30 \\
\%\end{array}$ & $\begin{array}{c}17 \\
\%\end{array}$ & $5 \%$ & $89 \%$ & $6 \%$ & $\begin{array}{c}300 \\
0\end{array}$ & $\begin{array}{c}2400 \\
0\end{array}$ & $\mathrm{CH}$ & $\begin{array}{c}2.8 \\
0\end{array}$ & $\begin{array}{c}0.29 \\
0\end{array}$ & $\begin{array}{c}40 \\
0\end{array}$ & 6 \\
\hline
\end{tabular}

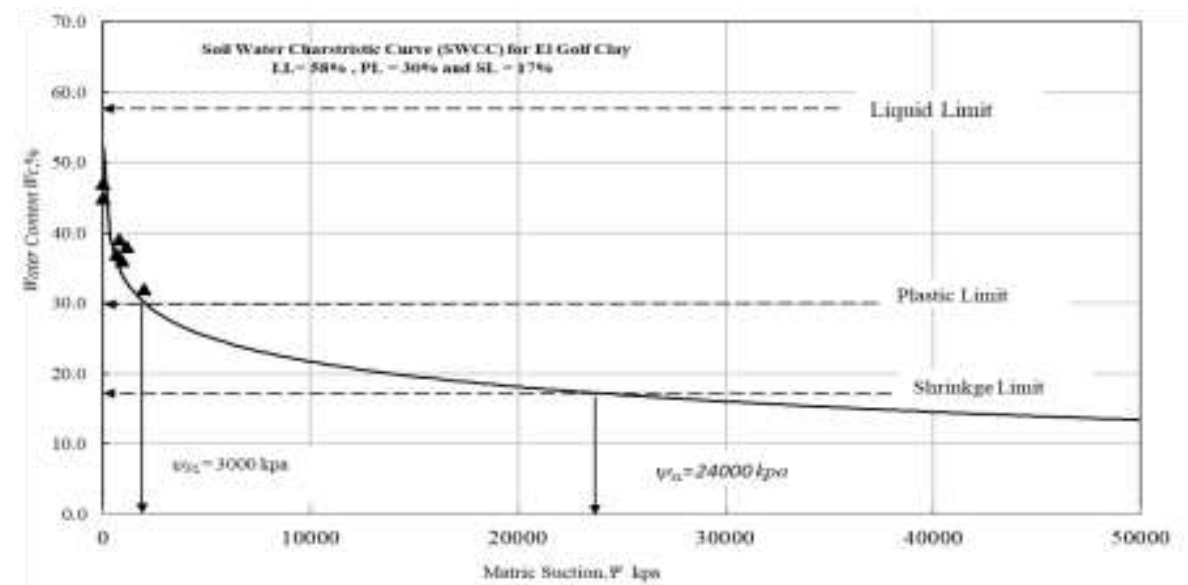

Figure -14 Soil -Water Characteristic Curve (SWCC) for El-Golf clay 


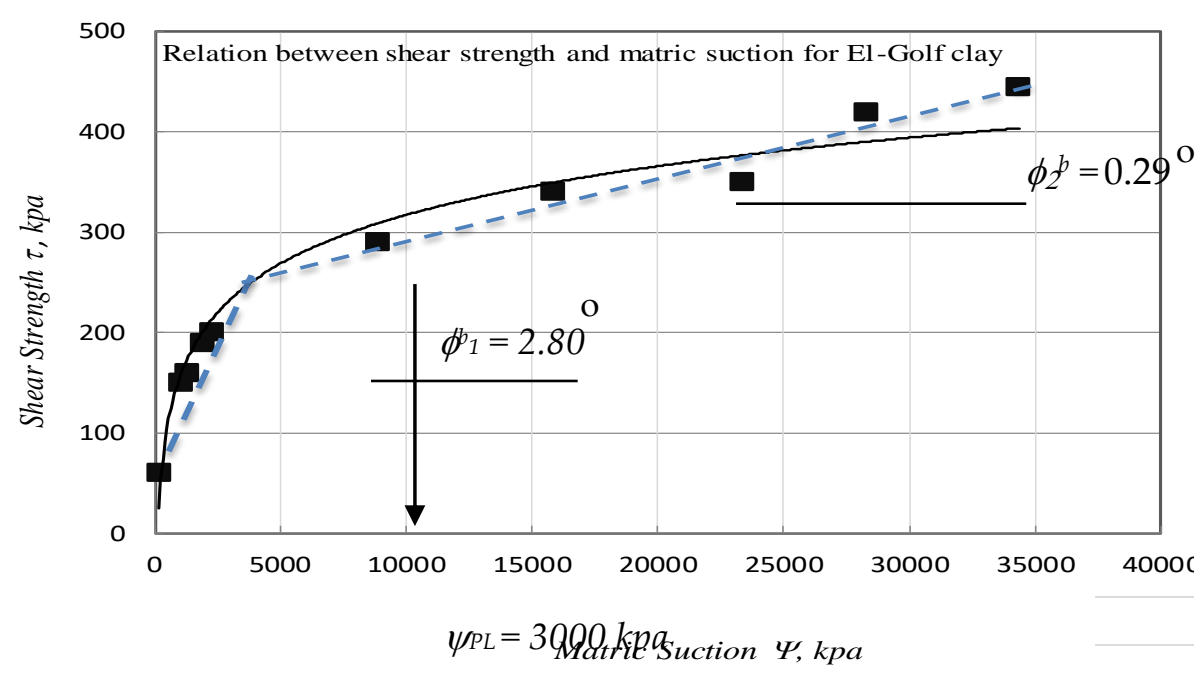

Figure -15 Shear strength variation with Matric Suction for El-Golf clay and at vertical stress $=65 \mathrm{kpa}$

Using data presented in Table 6 , equations 11 and 12 will take the following form:

$$
\begin{array}{ll}
\tau_{\text {lun. }}=5 c^{`}+0.377\left(\sigma_{v}\right)+0.049(\psi) & \text { Zone I from } P L<W c<L L \ldots \\
\tau_{\text {2un. }}=10 c^{`}+0.772\left(\sigma_{v}\right)+0.005(\psi) & \text { Zone II, from } W c<P L \ldots \ldots \ldots
\end{array}
$$

\section{Table-8 Results of measured and calculated unsaturated shear strength of El-Golf clay}

\begin{tabular}{|c|c|c|}
\hline Test No. & $\begin{array}{c}\text { Measured shear } \\
\text { strength from } \\
\text { equations }(\mathrm{kpa})\end{array}$ & $\begin{array}{c}\text { Calculated shear } \\
\text { strength from direct } \\
\text { shear tests }(\mathrm{kpa})\end{array}$ \\
\hline 1 & 70 & 74 \\
\hline 2 & 140 & 119 \\
\hline 3 & 150 & 130 \\
\hline 4 & 185 & 160 \\
\hline 5 & 200 & 181 \\
\hline 6 & 230 & 197 \\
\hline 7 & 290 & 256 \\
\hline 8 & 350 & 320 \\
\hline 9 & 390 & 362 \\
\hline
\end{tabular}


The data presented in Table 8 shown in Figure-16 to appear the differences between measured and calculated unsaturated shear strength. the predicted equation is less than the measured unsaturated shear strength by 7 .

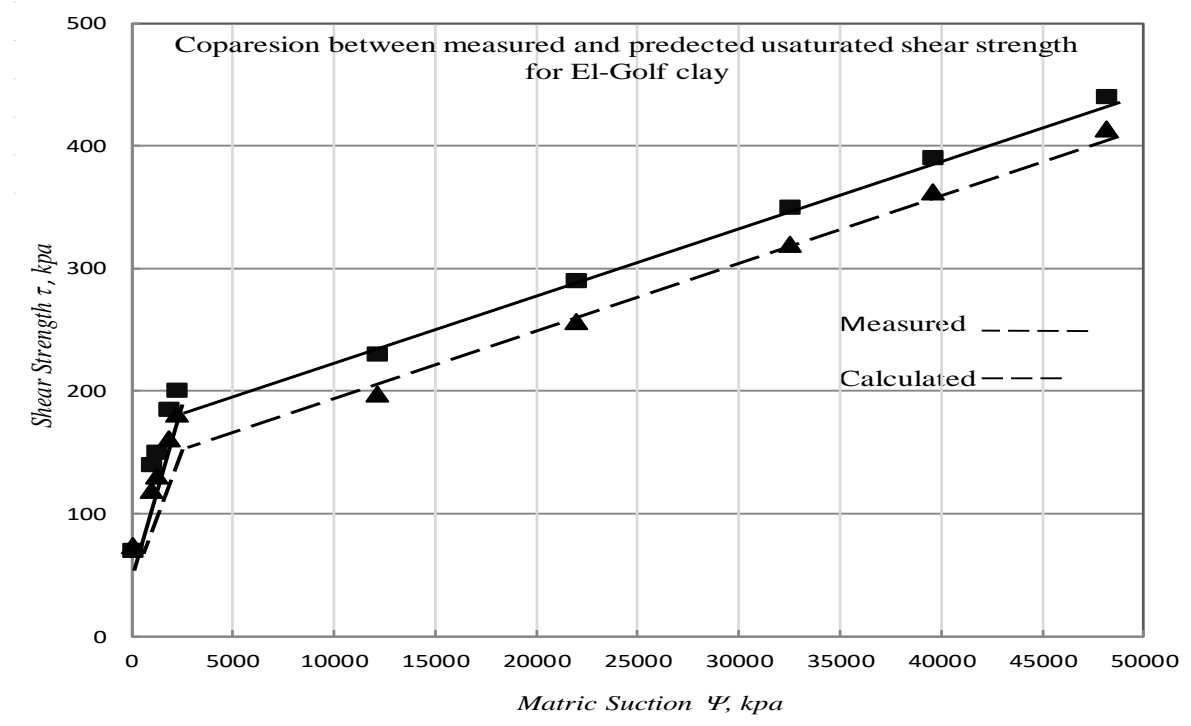

Figure -16 Calculated and measured shear strength for El-Golf clay at vertical stress $=65 \mathrm{kpa}$

\section{4-Conclusions}

(1) The shear strength of unsaturated cohesive soil can be predicted with two equations defined by two zones. The first zone for water content $W c>$ PL while the second zone for water content $W c<P L$. The shear envelope is approximated to two linear parts, the angle of internal friction due to matric suction of soil cohesion ranging from $\phi^{b}{ }_{l}=2.90^{\circ}$ for low plastic soil to $\phi^{b}{ }_{2}=0.28^{\circ}$ for high plastic soil. Granular soils that contain percentage of fines less than $35 \%$ the failure envelope is linear and $\phi^{\mathrm{b}}$ is constant value for all values of matric suction, $\phi^{b}$ about $1.19^{\circ}$.

(2) The unsaturated shear strength of soil can be presented in general form using three basic parameters $(c, \phi, \psi$ and $\sigma)$. Regarding to the equations model predicted using both the laboratory results and the Design -Expert program which are presented in Table-6, accordingly, the general equation for all types of soils will take the form:

$\tau_{\text {un. }}=A c^{`}+B\left(\sigma_{v}\right) \tan \phi+(\psi) \tan \phi^{b}$.

Where the coefficient $\mathrm{A}$ is function of clay fraction in soil,

the Constant $\mathrm{A}=1 \mathrm{x}$ (the clay fraction) in zone I and $=2 \mathrm{x}$ (clay fraction) in zone II for $\mathrm{CH}$ clays.

$=3 \mathrm{x}$ (clay fraction) in zone $\mathrm{I}$ and $=5 \mathrm{x}$ (clay fraction) in zone II for

CL clays.

$$
=5 \times \text { (clay fraction) for granular soils. }
$$


Coefficient $\mathrm{B}$ is a function of the angle of internal friction and texture of soil. According to the data presented in table -6 and table $1, \mathrm{~B}=\{1$ - (percentage of sand in soils/100)\}.

\section{REFERENCES}

1. Uchaipichat, A. (2014). Effect of suction on unconfined compressive strength of clayey soils with different sand contents. ARPN Journal of Engineering and Applied Sciences, 9(6)

2. Donald,I.B.(1957). Effective stresses in unsatyrated non-cohesive soils with controlled negative pore pressure.M.Eng. Sc. Thesis, University of Melbourne,Melbourne, Australia.

3. Khaboushan, E. A., Emami, H., Mosaddeghi, M. R., \& Astaraei, A. R. (2018). Estimation of unsaturated shear strength parameters using easily-available soil properties. Soil and Tillage Research, 184, 118-127.

4. Vanapalli, S.K. \& Fredlund, D.G. (2000). Comparison of empirical procedures to predict the shear strength of unsaturated soils uses the soil-water characteristic curve. Geo-Denver 2000, American Society of Civil Engineers, Special Publication, 99: 195-209.

5. Vanapalli, S. K. (2009, November). Shear strength of unsaturated soils and its applications in geotechnical engineering practice. In Keynote Address. Proc. 4th Asia-Pacific Conf. on Unsaturated Soils. New Castle, Australia (pp. 579-59

6. Kassab, A. et al. (2021). Shear Strength Behavior of Unsaturated Clay. Life Science Journal, 18(5).

7. Williams, P. J. (1982). The surface of the earth: an introduction to geotechnical science (Vol. 10). Addison-Wesley Longman Limited.

8. Bulut, R., Lytton, R. L., \& Wray, W. K. (2001). Soil suction measurements by filter paper. In Expansive clay soils and vegetative influence on shallow foundations (pp. 243-261).

9. Bicalho, K. V., Cupertino, K. F., \& Bertolde, A. I. (2011). Evaluation of suction-water content calibrations of filter paper. In 14th Pan-American Conference on Soil Mechanics and Geotechnical Engineering.

10. Fredlund, D. G., \& Xing, A. (1994). Equations for the soil-water characteristic curve. Canadian geotechnical journal, 31(4), 521-532.

11. Elsharief, A. M., Abdelaziz, O. A., \& Dafallaa, M. A. (2015). The influence of matric suction on the shear strength of highly plastic compacted swelling clays. Electronic Journal of Geotechnical Engineering, 20(25), 12555-12568.

12. Naser , M. et al. (2020) Ultimate Lateral Capacity of Large Diameter Monopiles Embedded in Sand 
13. Gardner, R. (1937). A method of measuring the capillary tension of soil moisture over a wide moisture range. Soil Science, 43(4), 277-284.

14. ASTM, D. (2010). 5298, Standard Test Method for Measurement of Soil Potential (suction) using Filter Paper. West Conshohocken, PA, USA: ASTM International.

15. Uchaipichat, A., \& Man Koksung, E. (2011). Bearing capacity characteristic of unsaturated granular soils. In Advanced Materials Research (Vol. 261, pp. 989-993). Trans Tech Publications Ltd. 